\title{
ANÁLISE FÍSICO-gUÍMICA E MICROBIOLÓGICA DO SUCO DE LARANJA MINIMAMENTE PROCESSADO ARMAZENADO EM LATA DE ALUMÍNIO'
}

\author{
Áurea Y. SUGAI ${ }^{2}$, Denise S. SHIGEOKA ${ }^{2}$, Gabriela G. BADOLATO ${ }^{2}$, Carmen C. TADINI ${ }^{2, *}$
}

\section{RESUMO}

Neste trabalho, suco de laranja natural foi pasteurizado em um trocador de calor a placas empregando três diferentes temperaturas de pasteurização: $82,5^{\circ} \mathrm{C} ; 85,0^{\circ} \mathrm{C}$ e $87,0^{\circ} \mathrm{C}$ e tempos de retenção variando de 11 a $59 \mathrm{~s}$, para se obter um produto minimamente processado. Um estudo comparativo foi realizado no suco de laranja armazenado em latas de alumínio em relação ao mesmo produto armazenado em garrafas PEAD, sob refrigeração, por um período de 21 dias. Análises de graus Brix, pH, acidez, sólidos insolúveis e totais e análises microbiológicas foram realizadas em amostras logo após o processamento e durante o período de armazenamento. As propriedades fisico-químicas do suco de laranja pasteurizado apresentaram diferenças devido as diferenças detectadas na matériaprima ao longo do período do estudo. O parâmetro de pasteurização mais apropriado para o suco de laranja natural foi $87,0^{\circ} \mathrm{C}$ e com tempo de retenção variando de acordo com o pH do suco. Para $\mathrm{pH} 4,0$ o tempo de retenção requerido foi maior. De acordo com os resultados, uma vida-de-prateleira de 15 dias foi determinada para o suco processado nas condições acima.

Palavras-chave: suco de laranja; pasteurização; análise físico-química; análise microbiológica; vida-de-prateleira; embalagem.

\section{SUMMARY}

PHYSICO-CHEMICAL AND MICROBIOLOGICAL ANALYSES OF MINIMALLY PROCESSED ORANGE JUICE STORED IN ALUMINIUM CANS. In this work, single-strength orange juice was pasteurized in a plate heat exchanger using three different temperatures: $82.5^{\circ} \mathrm{C}$, $85.0^{\circ} \mathrm{C}$ and $87.0^{\circ} \mathrm{C}$ and holding times varying from 11 to $59 \mathrm{~s}$ in order to obtain a minimally processed product. A comparison among orange juice samples stored in aluminium cans and in polyethylene bottles under refrigerated conditions for 21 days was carried out. Degree of Brix, acidity, pH, insoluble and total solids, and microbiological analyses were conducted soon after processing and during the storage period. The physico-chemical properties of the pasteurized orange juice showed differences due to variations in the raw material during the period of study. The most appropriate pasteurization temperature for orange juice was $87.0^{\circ} \mathrm{C}$, with the holding time varying according to $\mathrm{pH} ; \mathrm{pH} 4.0$ required longer holding times. According to the results, a shelf life of 15 days was determined for the processed orange juice, under the above conditions.

Keywords: orange juice; pasteurization; physico-chemical analysis; microbiological analysis; shelf-life; package.

\section{1 - INTRODUÇÃO}

Atualmente o Brasil é o maior produtor mundial de suco de laranja, sendo este um de seus principais produtos de exportação. No Estado de São Paulo existem 11 indústrias processadoras de suco, que são responsáveis pela geração de 8 mil empregos diretos e 420 mil empregos no campo. A título de ilustração, a cada dez copos de suco que se tomam no mundo, exceto os EUA, oito são brasileiros [14].

Combinação perfeita entre sabor e saúde, o suco de laranja possui vitaminas e nutrientes suficientes para ser considerado um alimento saudável pelo FDA (Food and Drug Administration - EUA), além de possuir quantidades de gordura, colesterol e sódio dentro dos padrões estabelecidos para ser considerado como tal. Seus principais nutrientes são: Vitaminas C e B, potássio, fibra e ferro [15].

Estudo realizado por ALVES \& GARCIA [1] aponta que até 1991 praticamente não existiam no Brasil sucos de frutas refrigerados prontos para beber. Segundo PASTORE [16], ocorreu uma explosão com respeito ao

\footnotetext{
Recebido para publicação em 08/08/2000. Aceito para publicação em $07 / 02 / 2002$

2. ESCOLA POLITÉCNICA DA USP, Departamento de Engenharia Quimica, Laboratório de Engenharia de Alimentos, Caixa Postal 61548, CEP: 05424-970,São Paulo,SP.E-mail:catadini@usp.br * A quem a correspondencia deve ser enviada.
}

aparecimento de "carrinhos refrigerados em forma de laranja que vendem suco em garrafa de plástico". Atualmente, o suco de laranja refrigerado pronto para beber é encontrado no mercado principalmente em embalagens cartonadas. Este pode ser natural fresco, natural pasteurizado, ou ainda um suco reconstituído do concentrado. É possivel encontrar ainda suco processado termicamente, em embalagem cartonada, armazenado à temperatura ambiente.

Dentre as embalagens plásticas, a garrafa de polietileno de alta densidade (PEAD) é utilizada no Brasil para este tipo de produto. Segundo ALVES \& GARCIA [1], este material é responsável por uma vida útil muito reduzida do produto, uma vez que possui grande permeabilidade a gases.

O suco de laranja armazenado em lata ainda é novidade no Brasil. Segundo trabalho realizado por SHIGEOKA [18], atualmente existe grande interesse na utilização de latas de aluminio, já que estas apresentam uma série de vantagens como economia de espaço e de energia, redução no custo do transporte, maior giro de estoque e maior proteção ao meio ambiente.

O suco de laranja natural apresenta, porém, uma vida-de-prateleira muito limitada. Estudos brasileiros mostraram que grande parte do suco de laranja natural comercializado tem sua qualidade comprometida quanto aos aspectos microbiológicos [3, 12, 17, 19]. Os dados sugerem a necessidade do processamento do suco de 
laranja natural, de forma a aumentar a sua vida-de-prateleira e garantir a saúde do consumidor, mas mantendo suas características organolépticas mais próximas às do produto natural "fresco", seguindo uma grande tendência de preferência do consumidor, em especial o brasileiro, a quem o suco de laranja natural é muito acessível $[1,8,11]$.

O processo de extração e pasteurização de suco de laranja natural, combinado a uma embalagem e temperatura de armazenamento adequadas, torna possivel a obtenção de um produto "minimamente processado".

Segundo CORREA NETO \& FARIA [8], a qualidade do suco é influenciada basicamente por fatores microbiológicos, enzimáticos, quimicos e físicos, que comprometem suas características organolépticas e nutricionais.

O suco de laranja é considerado um alimento ácido e, portanto, sua deterioração de natureza microbiológica está associada a proliferação de bactérias lácticas, leveduras e fungos que the conferem sabor e odor indesejáveis $[10,13]$.

O suco de laranja pasteurizado encontrado no mercado é composto de diferentes variedades de laranja. Na determinação de seus padrões de identidade e qualidade é enquadrado como "suco de laranja", que é definido como: "bebida não fermentada e não diluída, obtida da parte comestivel da laranja (Citrus sinensis), através de processo tecnológico adequado". Dentre outras características, deve apresentar teor de sólidos solúveis em ${ }^{\circ}$ Brix de no mínimo 10,5 e a relação de sólidos solúveis em ${ }^{\circ}$ Brix / acidez em g/ 100g de ácido cítrico anidro minima de 7,0 [6].

A princípio é importante lembrar que a mais recente resolução da Agência Nacional de Vigilância Sanitária (RDC no 12) não estabelece limites de bolores e leveduras para suco de laranja pasteurizado [7]. O nivel de tratamento térmico do suco de laranja é estabelecido utilizando a pectinesterase como parâmetro, que é mais termorresistente que os microrganismos presentes [20].

Este trabalho teve como objetivo estudar a vida-deprateleira do suco durante um periodo de 21 dias e, desta forma, comparar dois tipos de embalagem, dando continuidade ao trabalho realizado por SHIGEOKA [18]. Na primeira etapa do projeto o suco foi armazenado em garrafas de PEAD ( polietileno de alta densidade ) e na segunda etapa foram utilizadas latas de aluminio.

\section{2 - MATERIAL E MÉTODOS}

\section{1 - Material}

As laranjas utilizadas no processamento do suco foram da variedade Pêra (Citrus sinensis (L.) Osbeck), adquiridas no CEAGESP, na cidade de São Paulo.

\section{2 - Métodos}

\subsection{1 - Processamento}

As laranjas, após seleção e lavagem, foram submetidas ao processo de extração do suco em máquina extra- tora FMC "fresh" e o suco foi em parte reservado para amostragem do suco natural não pasteurizado e em parte conduzido diretamente para o tanque de alimentação do trocador de calor a placas ARMFIELD, FT 43-A, provido de sistemas de aquecimento com água quente e sistema de água gelada para resfriamento, e de dois tubos de retenção $(0,078 \mathrm{~L}$ e 0,24 L). A temperatura de pasteurização foi monitorada e controlada por um sistema de controle de temperatura através de microprocessador com ação $\mathrm{P}+\mathrm{I}+\mathrm{D}$. As diferentes condições de processo (temperatura de pasteurização - tempo de retenção) conduzidas foram de acordo com o delineamento experimental definido em BADOLATO [5], ou seja, temperaturas de pasteurização: $82,5^{\circ} \mathrm{C} ; 85,0^{\circ} \mathrm{C}$ e $87,0^{\circ} \mathrm{C}$ e para cada temperatura de pasteurização os seguintes tempos de retenção (em s): 11,09; 12,29; 13,87; 15,82; 18,49; 35,$13 ; 43,91 ; 50,09$ e 58,55.

Os sucos de laranja natural pasteurizado e natural não processado foram acondicionados em latas de aluminio e garrafas de PEAD previamente lavadas com água destilada. Após o enchimento e fechamento das embalagens, as mesmas foram armazenadas em geladeira. Para cada condição [temperatura de pasteurização - tempo de retenção] estudada, foram coletadas 8 amostras do suco para realização semanal das análises físico-químicas e microbiológicas, em duplicata, no 1으, 8으, 15으 e 21은 dia do armazenamento. Análises em amostras do suco não processado também foram conduzidas da mesma maneira.

\subsection{2 - Análises físico químicas:}

- $\quad \mathrm{pH}$ : Medido em pH-Stat Radiometer modelo PHM290.

- Acidez titulável: Realizado conforme o método da AOAC, conduzido no pH-Stat até atingir $\mathrm{pH}$ de 8,3 (referente ao pH de mudança de coloração do indicador fenolftaleína) [4].

- $\quad$ Brix: Medido em refratômetro marca Carlzeiss Jena (711849), com correções de acidez e temperatura [13].

- Sólidos totais: Segundo método da AOAC [4].

- Sólidos insolúveis em água: Segundo método da AOAC [4].

\subsection{3 - Análises microbiológicas:}

- Contagem total de bactérias mesofilicas através do método de contagem de placas padrão: Realizada em duplicata de acordo com a metodologia proposta pela APHA, utilizando-se Orange Serum Ágar como meio de cultura e incubação da amostra em estufa a $35^{\circ} \mathrm{C}$ por 48 horas [2, 9].

- Contagem de leveduras e bolores: Realizada em duplicata, de acordo com a metodologia proposta pela APHA, utilizando-se Potato Dextrose Ágar como meio de cultura, incubando-se a amostra à temperatura ambiente por 5 dias [2]. 


\section{3 - RESULTADOS E DISCUSSÃO}

Dezenove processamentos de extração e pasteurização do suco foram conduzidos e para cada processamento foram empregados três diferentes parâmetros de temperatura de pasteurização - tempo de retenção resultando em 57 diferentes tratamentos. Cerca de 1200kg de laranja foram processados produzindo cerca de 750L de suco, sendo amostrados em torno de $67 \mathrm{~L}$ para as análises físico-químicas e microbiológicas.

Análise de variância dos resultados das análises fisico-químicas do suco de laranja natural não pasteurizado indicou que houve variação com respeito a acidez, expressa como \% de ácido cítrico $(0,65 \% \pm 0,02),{ }^{\circ}$ Brix $(10,99 \pm 0,16), \mathrm{pH}(3,85 \pm 0,06)$, teores de sólidos insolúveis e totais $(0,36 \%$ S.I. $\pm 0,01 ; 11,39 \%$ S.T. $\pm 0,20)$, em função da safra da laranja, ao nivel de confiança de 95\%, confirmado pelo teste Tukey HSD.

Análises de variância foram realizadas para verificar quais fatores influenciaram significativamente os resultados das análises físico-químicas conduzidas em amostras de suco pasteurizado a diferentes tratamentos.

A Tabela 1 apresenta o resultado da ANOVA aplicada nos resultados da porcentagem de acidez, indicando que a temperatura influenciou estatisticamente os resultados, ao nivel de confiança de $95 \%$, confirmado pelo teste Tukey HSD. Apesar da temperatura ter influenciado a acidez do suco, conforme indica a ANOVA, já vimos que a própria matéria-prima apresentou variação de acidez durante o periodo de processamento, uma vez que o suco foi processado sem a preocupação de padronizar a relação ${ }^{\circ} \mathrm{Brix} /$ acidez.

TABELA 1. Análise de variância aplicada nos valores obtidos de acidez do suco de laranja natural pasteurizado.

\begin{tabular}{lccccc}
\hline Fonte da variação & $\begin{array}{c}\text { Soma dos } \\
\text { Quadrados }\end{array}$ & $\begin{array}{c}\text { Graus de } \\
\text { liberdade }\end{array}$ & $\begin{array}{c}\text { Quadrado } \\
\text { Médio }\end{array}$ & Razão F & Valor de P \\
\hline Temperatura & 0,1487 & 2 & 0,0743 & 3,68 & 0,0285 \\
Tempo & 0,2999 & 8 & 0,0375 & 1,86 & 0,0747 \\
Resíduo & 2,1200 & 105 & 0,0202 & & \\
\hline TOTAL (corrigido) & 2,6113 & 115 & & Média: $0,63 \% \pm 0,14$ \\
\hline
\end{tabular}

A Tabela 2 apresenta o resultado da ANOVA aplicada nos resultados de graus Brix, indicando que o tempo de retenção influenciou estatisticamente os resultados, ao nivel de confiança de $95 \%$, confirmado pelo teste Tukey HSD. A variabilidade do valor de Brix do suco pode ser explicada em princípio pela variação do Brix da matéria-prima e principalmente pelo fato de que quanto menor o tempo de retenção, maior foi a velocidade mássica no canal formado pela corrente do fluido entre duas placas, provocando um atrito entre as partículas do suco e a parede da placa. Desta forma, para maiores velocidades mássicas, houve maior quebra da polpa provocando um acréscimo no valor do teor de sólidos solúveis, lido pelo índice refratométrico. Os valores médios do Brix diminuíram com o aumento do tempo de retenção.
TABELA 2. Análise de variância aplicada nos valores obtidos de graus Brix do suco de laranja natural pasteurizado.

\begin{tabular}{lccccc}
\hline Fonte da variação & $\begin{array}{c}\text { Soma dos } \\
\text { Quadrados }\end{array}$ & $\begin{array}{c}\text { Graus de } \\
\text { liberdade }\end{array}$ & $\begin{array}{c}\text { Quadrado } \\
\text { Médio }\end{array}$ & Razão F & Valor de P \\
\hline Temperatura & 1,2501 & 2 & 0,6250 & 0,87 & 0,4226 \\
Tempo & 12,3846 & 8 & 1,5481 & 2,15 & 0,0373 \\
Resíduo & 75,5792 & 105 & 0,7198 & & \\
\hline TOTAL (corrigido) & 88,9633 & 115 & & Média: $10,88 \pm 0,85$ \\
\hline
\end{tabular}

A Tabela 3 apresenta o resultado da ANOVA aplicada nos resultados do $\mathrm{pH}$, indicando que tanto a temperatura de pasteurização quanto o tempo de retenção influenciaram estatisticamente os resultados, ao nivel de confiança de 95\%, confirmado pelo teste Tukey HSD. Esta variabilidade do valor de $\mathrm{pH}$ do suco provavelmente se deve a própria variação da matéria-prima laranja, como visto anteriormente.

TABELA 3. Análise de variância aplicada nos valores obtidos do $\mathrm{pH}$ do suco de laranja natural pasteurizado.

\begin{tabular}{lccccc}
\hline Fonte da variação & $\begin{array}{c}\text { Soma dos } \\
\text { Quadrados }\end{array}$ & $\begin{array}{c}\text { Graus de } \\
\text { liberdade }\end{array}$ & $\begin{array}{c}\text { Quadrado } \\
\text { Médio }\end{array}$ & Razão F & Valor de P \\
\hline Temperatura & 0,4421 & 2 & 0,2210 & 4,25 & 0,0168 \\
Tempo & 1,0963 & 8 & 0,1370 & 2,64 & 0,0113 \\
Resíduo & 5,4599 & 105 & 0,0520 & & \\
\hline TOTAL (corrigido) & 7,3210 & 115 & & Média: 3,78 0,23 \\
\hline
\end{tabular}

Análises ANOVA aplicadas nos resultados dos teores de sólidos insolúveis e totais indicaram que nenhum fator influenciou estatisticamente os resultados, ao nivel de confiança de $95 \%$, confirmado pelo teste Tukey HSD.

As médias e desvios padrão obtidos das análises físico químicas do suco natural não processado e do suco natural pasteurizado estão apresentados na Tabela 4.

Observando a Tabela 4, é possivel verificar que os valores obtidos para a média dos dados fisico-químicos do suco natural não processado são muito próximos aos obtidos para o suco pasteurizado. Os valores do desvio padrão correspondentes aos da média do suco pasteurizado foram maiores que aqueles obtidos para o suco não processado, caracterizando que os processamentos térmicos provocaram modificações no produto final.

Em relação às médias, verificamos que tanto o suco não processado quanto o suco pasteurizado estão dentro dos padrões de identidade e qualidade de "suco de laranja”, no que diz respeito ao $\operatorname{Brix}(>10,5)$ e a relação Brix/acidez (>7) [6].

Análises estatísticas indicaram que o tipo de embalagem empregada (PEAD ou lata de Al) influenciou a aci$\operatorname{dez}(0,54 \% \pm 0,07)$, ${ }^{\circ}$ Brix $(11,23 \pm 0,43)$ e $\mathrm{pH}(3,93 \pm$ $0,16)$ do suco armazenado durante 21 dias, sob refrigeração. O tempo de armazenamento, no entanto, somente influenciou a acidez e o pH do suco. Apesar da ANOVA indicar que os fatores acima influenciaram a acidez e o 
$\mathrm{pH}$ do suco, pode ser observado que ocorreu um erro experimental (resíduo) muito baixo, devido a precisão dos resultados obtidos nas medições conduzidas no $\mathrm{pH}-\mathrm{Stat}$, além da própria variação da matéria-prima. A variabilidade do valor de Brix do suco pode ser explicada pelo fato que o emprego da garrafa $\mathrm{PEAD}$ foi em um período da safra da laranja diferente daqueles ensaios conduzidos cujas amostras foram embaladas em latas de alumínio. Para comparar os resultados utilizando análise estatística, os mesmos foram normalizados.

TABELA 4. Valores da média e desvio padrão obtidos para o suco natural não processado e para o suco natural pasteurizado a diferentes tratamentos.

\begin{tabular}{lcccc}
\hline & \multicolumn{2}{c}{ Suco não processado } & \multicolumn{2}{c}{ Suco pasteurizado } \\
\hline & Média & Des vio padrão & Média & Desvio padrão \\
\hline Acidez (\% ácido cítrico) & 0,65 & 0,02 & 0,63 & 0,14 \\
${ }^{\circ}$ Brix & 10,99 & 0,16 & 10,88 & 0,85 \\
pH & 3,85 & 0,06 & 3,78 & 0,23 \\
Sólidos insolúveis (\%) & 0,36 & 0,01 & 0,32 & 0,13 \\
Sólidos totais $\quad(\%)$ & 11,39 & 0,20 & 11,39 & 1,09 \\
\hline
\end{tabular}

A Tabela 5 apresenta o resultado da ANOVA aplicada nos resultados da contagem total de bactérias mesofilicas do suco processado em relação a contagem total do suco não processado $\left(\mathrm{C} / \mathrm{C}_{0}\right)$, indicando que somente a vida de prateleira influenciou estatisticamente os resultados, ao nível de confiança de $95 \%$, confirmado pelo teste Tukey HSD.

TABELA 5. Análise de variância aplicada nos valores obtidos da contagem total de bactérias mesofilicas do suco processado em relação a contagem total do suco não processado $\left(\mathrm{C} / \mathrm{C}_{0}\right)$, durante o período de armazenamento em geladeira.

\begin{tabular}{lccccc}
\hline Fonte da variação & $\begin{array}{c}\text { Soma dos } \\
\text { Quadrados }\end{array}$ & $\begin{array}{c}\text { Graus de } \\
\text { liberdade }\end{array}$ & $\begin{array}{c}\text { Quadrado } \\
\text { Médio }\end{array}$ & Razão F & Valor de P \\
\hline Embalagem & 109,684 & 1 & 109,684 & 0,06 & 0,8094 \\
Temperatura & 8491,6 & 3 & 2830,53 & 1,51 & 0,2147 \\
Vida-de-prateleira & 23655,5 & 3 & 7885,16 & 4,19 & 0,0067 \\
Resíduo & 338386,0 & 180 & 1879,92 & & \\
\hline TOTAL (corrigido) & 370499,0 & 187 & & Média: $8,04 \pm 4,34$ \\
\hline
\end{tabular}

A Figura 1 ilustra claramente a evolução da contagem total das bactérias mesofilicas em relação a contagem total do suco não processado, aumentando com o aumento do tempo de armazenamento. É significativo o aumento após 15 dias de armazenamento sob refrigeração.

A Tabela 6 apresenta o resultado da ANOVA aplicada nos resultados da contagem de bolores e leveduras do suco processado em relação ao suco não processado $\left(\mathrm{B} / \mathrm{B}_{0}\right)$ indicando que apenas a temperatura de processo influenciou estatisticamente os resultados, ao nivel de
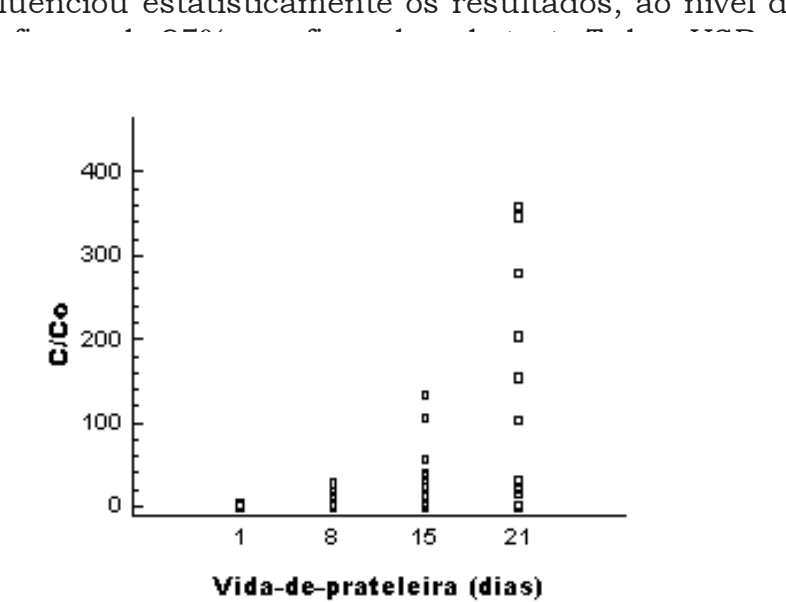

FIGURA 1. Contagem total de bactérias mesofilicas do suco de laranja natural processado em relação a contagem total do suco não processado $\left(\mathrm{C} / \mathrm{C}_{0}\right)$, armazenado sob refrigeração por até 21 dias.

TABELA 6. Análise de variância aplicada nos valores obtidos da contagem de bolores e leveduras do suco processado em relação a contagem do suco não processado $\left(\mathrm{B} / \mathrm{B}_{0}\right)$, durante o periodo de armazenamento, sob refrigeração.

\begin{tabular}{lccccc}
\hline Fonte da variação & $\begin{array}{c}\text { Soma dos } \\
\text { Quadrados }\end{array}$ & $\begin{array}{c}\text { Graus de } \\
\text { liberdade }\end{array}$ & $\begin{array}{c}\text { Quadrado } \\
\text { Médio }\end{array}$ & Razão F & Valor de P \\
\hline Embalagem & 0,9192 & 1 & 0,9192 & 2,87 & 0,0918 \\
Temperatura & 36,38 & 3 & 12,1267 & 37,90 & 0,0000 \\
Vida-de-prateleira & 0,3658 & 3 & 0,1219 & 0,38 & 0,7667 \\
Resíduo & 57,5942 & 180 & 0,3200 & & \\
\hline TOTAL (corrigido) & 97,3659 & 187 & & Média: $0,37 \pm 0,06$ \\
\hline
\end{tabular}

A Figura 2 indica claramente a diminuição da contagem de bolores e leveduras em relação a temperatura do processo, diminuindo com o aumento da temperatura. É sensivel a diminuição da contagem já à temperatura de $82,5^{\circ} \mathrm{C}$.

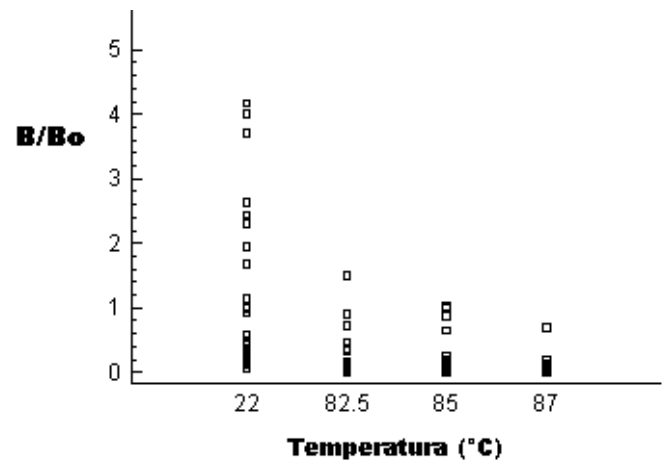

FIGURA 2. Contagem de bolores e leveduras do suco de laranja natural processado em relação a contagem do suco não processado $\left(\mathrm{B} / \mathrm{B}_{0}\right)$, armazenado sob refrigeração, por até 21 dias. 
A Figura 3 ilustra os valores obtidos na contagem de bolores e leveduras em UFC/ mL para o suco natural não processado armazenado sob refrigeração. Observando a Figura 3, nota-se que grande parte do suco não processado armazenado sob refrigeração, por até 21 dias, apresentou uma contagem de bolores e leveduras superior a 1000.

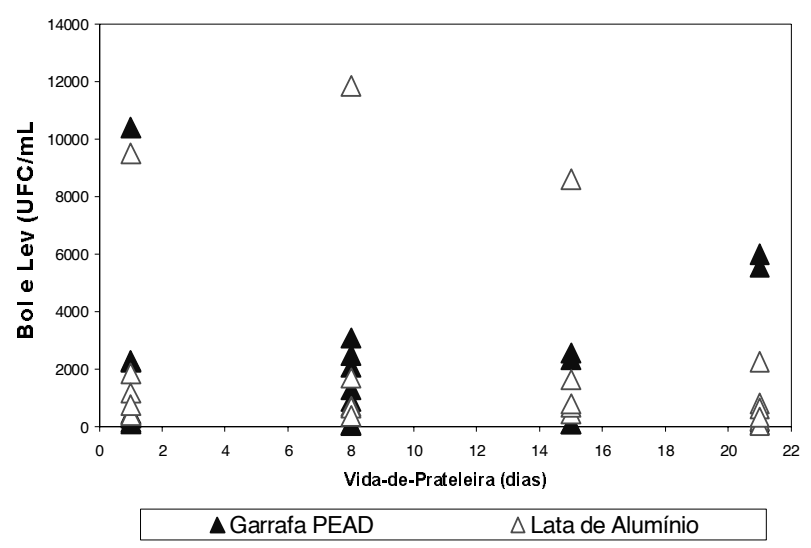

FIGURA 3. Contagem de bolores e leveduras em suco de laranja natural não processado, armazenado em garrafa de PEAD ou lata de alumínio por 21 dias, sob refrigeração.

A Figura 4 ilustra os valores absolutos obtidos na contagem de bolores e leveduras em $\mathrm{UFC} / \mathrm{mL}$ para o suco natural pasteurizado armazenado sob refrigeração.

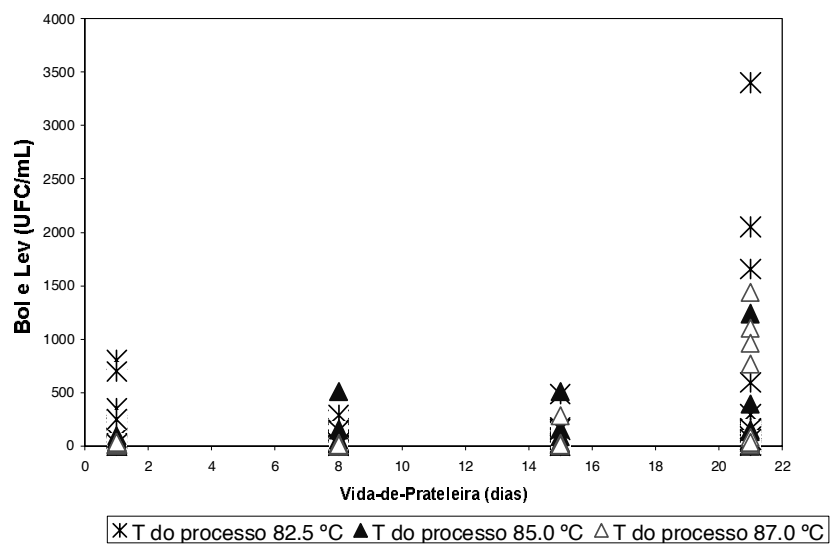

FIGURA 4. Contagem de bolores e leveduras em suco de laranja natural processado, a diferentes temperaturas de pasteurização, armazenado em garrafa de PEAD ou lata de alumínio por 21 dias sob refrigeração.

Estudos sobre a inativação da pectinesterase foram conduzidos por BADOLATO [5] na pasteurização do suco de laranja natural nas condições descritas neste traba1ho. O parâmetro encontrado mais apropriado com respeito a inativação enzimática foi da temperatura de pasteurização de $87,0^{\circ} \mathrm{C}$ e tempo de retenção variando conforme o $\mathrm{pH}$ do suco. Para $\mathrm{pH}$ 4,0 o tempo de retenção requerido foi maior que para valores de $\mathrm{pH} 3,4$ ou 4,5, caracterizando um valor de $\mathrm{pH}$ como ponto de maior resistência térmica da pectinesterase.

\section{4 - CONCLUSÕES}

As propriedades físico-químicas analisadas do suco de laranja pasteurizado apresentaram diferenças devido às variações detectadas na matéria-prima ao longo do período do estudo.

O suco de laranja natural minimamente processado obtido neste estudo está dentro dos padrões de identidade e qualidade de "suco de laranja" estabelecidos pela legislação brasileira vigente.

Os valores da razão da contagem de bactérias mesofilicas do produto em relação à contagem da matéria-prima $\left(\mathrm{C} / \mathrm{C}_{0}\right)$ analisados estatisticamente, variaram apenas em relação a vida-de-prateleira, aumentando consideravelmente com o aumento do tempo de armazenamento. Para os resultados obtidos da razão da contagem de bolores e leveduras do produto em relação à contagem da matéria-prima $\left(B / B_{0}\right)$, a análise estatística indicou diferenças em relação à temperatura empregada no processo térmico.

\section{5 - REFERÊNCIAS BIBLIOGRÁFICAS}

[1] ALVES, R. M. V.; GARCIA, E. E. C. Embalagem para sucos de frutas. Coletânea do ITAL, v. 2, n. 23, p. 105-122, 1993.

[2] AMERICAN PUBLIC HEALTH ASSOCIATION - APHA. Compendium of methods for the microbiological examination of foods. 3 ed. Washington, D.C., p1219, 1992.

[3] ARRUdA, W. R.; CARDonhA, A. M. S. Avaliação microbiológica de sucos de laranja in natura comercializados na cidade de Natal RN. In: CONGRESSO BRASILEIRO DE CIÊNCIA E TECNOLOGIA DE ALIMENTOS, 16., Rio de Janeiro. Anais. [Em CD-Rom] Trabalho n. 558, 1998.

[4] ASSOCIATION OF OFFICIAL ANALYTICAL CHEMISTS. AOAC Official methods of analysis. 16.ed. Washington, D.C., v. 2, 1995.

[5] BADOLATO, G. G. Tratamento térmico mínimo do suco de laranja natural: cinética da inativação da pectinesterase. São Paulo. 2000, 157p. Dissertação de Mestrado. Escola Politécnica da Universidade de São Paulo. Departamento de Engenharia Quimica (USP).

[6] BRASIL. Leis, decretos, etc. Decreto no 2314 de 4 de setembro de 1997. Diário Oficial, Brasília. Regulamento técnico geral para fixação dos padrões de identidade e qualidade para polpa de fruta pelo art. 159 da Lei oㅡ 8918, de jul. 1994, 10 jan. 2000.

[7] BRASIL. Resoluções RDC - 2001. [Online] Disponivel: http:/ /www.anvisa.gov.br/legis/resol/12 01rdc.htm. Arquivo capturado em agosto de 2001.

[8] CORREA NETO, R. J.; FARIA, J. A. F. Fatores que influenciam na qualidade do suco de laranja. Ciênc. e Tecnol. de Alim., v. 19, n. 1, p. 153-160, 1999.

[9] FELLERS, J. P. Shelf life and quality of freshly squeezed, unpasteurized, polyethylene-bottled citrus juice. Journal of Food Science, v. 53, n. 6, p.1699-702, 1988.

[10] HATCHER, W. S. et al. Fruit beverages. In: VANDERZAN, C.; SPlitTSTOESSER, D. F., eds. Compendium of methods for the microbiological examinations of foods. 3.ed. Washington, American Public Health Association, p. 953-60, 1992. 
[11] FOX, K. Innovations in citrus processing. Fruit Processing, v. 11, n. 4, p. 338-348, 1994.

[12] IHA, M. H. et al. Avaliação físico-química e higiênicosanitária do suco de laranja não pasteurizado, engarrafado e comercializado nas cidades de Ribeirão Preto e Araraquara - SP. In: CONGRESSO BRASILEIRO DE CIÊNCIA E TECNOLOGIA DE ALIMENTOS, 16., Rio de Janeiro. Anais. [Em CD-Rom] Trabalho no 292, 1998.

[13] KIMBALL, D. A. Citrus processing quality control and technology. New York, Chapman \& Hall-ITP, 1991.

[14] OLIVEIRA, R. Exportação de suco deve bater recorde. Folha de São Paulo, Agrofolha, 15 jun. 1999, p. 1.

[15] ONJUS. $100 \%$ advantage [On line] Disponivel: http:// www.onjus.com/advantage.html. Arquivo capturado em 1998.

[16] PASTORE, K. Banho de suco. Veja, v. 39, n. 1473, p. 75, 1996.

[17] RUSCHEL, C. K. et al. Qualidade microbiológica e físicoquímica de sucos de laranja comercializados nas vias públicas de Porto Alegre/RS. Ciênc. e Tecnol. de Alim., n. 21, v. 1 , p. 94-97, 2001.
[18] SHIGEOKA, D. S. Tratamento térmico mínimo do suco de laranja natural: Estudo da viabilidade de armazenamento em latas de alumínio. São Paulo. 1999, 55p. Dissertação de Mestrado - Escola Politécnica, Universidade de São Paulo (USP)

[19] TOCCHINI, R. P.; NISIDA, A. L. A. C.; BERBARI, S. A. G. Estabilidade do suco de laranja refrigerado, em condições definidas de distribuição e comercialização. Boletim SBCTA, n. 27, v. 2, p. 128-32, 1993.

[20] VERSTEEG, C. et al. Thermostability and orange juice cloud destabilizing properties of multiple pectinesterase from orange. Journal of Food Science, v. 45, p. 969-71, 1980.

\section{6 - AGRADECIMENTOS}

Os autores agradecem à FAPESP (Fundação de Amparo à Pesquisa do Estado de São Paulo) e ao CNPq (Conselho Nacional de Desenvolvimento Científico e Tecnológico) pelo apoio financeiro.

Os autores agradecem o apoio técnico e o fornecimento das latas a LATASA Latas de Alumínio S/A. 